\title{
Sex-specific Changes in Brain Estrogen Metabolism Induced by Acute Trimethyltin Exposure
}

\author{
JUNG HO LEE ${ }^{1}$, SUNG-HEE CHO ${ }^{2}$, EUN HYE JANG ${ }^{1}$ and SOON AE KIM ${ }^{1}$ \\ ${ }^{1}$ Department of Pharmacology, School of Medicine, Eulji University, Daejeon, Republic of Korea; \\ ${ }^{2}$ Chemical Analysis Center, Korea Research Institute of Chemical Technology (KRICT), Daejeon, Republic of Korea
}

\begin{abstract}
Background/Aim: In this study, we investigated sex-specific effects of acute exposure to trimethyltin, a known neurotoxicant on metabolic steroids. Materials and Methods: We administered intraperitoneally $2.3 \mathrm{mg} / \mathrm{kg}$ trimethyltin to 4-week-old male mice and measured the levels of metabolic steroids $24 \mathrm{~h}$ after treatment. We also measured $m R N A$ and protein levels of cytochrome P450 1B1 using real-time polymerase chain reaction and western blotting. Results: Cortisol levels in the cortex increased in both sexes following acute trimethyltin exposure. The estradiol levels decreased, and the 4-hydroxyestradiol levels increased only in females. We also observed increased cytochrome P450 $1 B 1$ mRNA and protein levels only in the female cortex. Conclusion: Acute trimethyltin exposure induces distinct sexspecific metabolic changes in the brain before significant sexual maturation.
\end{abstract}

Trimethyltin (TMT), a tri-substituted organotin, is a neurotoxicant that causes neuronal degeneration in human's and animal's central nervous system by inducing oxidative stress and apoptosis (1). TMT causes neuronal loss in specific brain regions such as the dentate gyrus, olfactory bulb, anterior olfactory nucleus, and frontal cerebral cortex $(2,3)$. Exposure to high concentrations of TMT due to accident or experimental treatments induces characteristic behavioral changes in rodents $(4,5)$. There have been many studies on the effects of TMT on the brain of adult animals or neonatal development (5-7), but relatively few studies on the impact on juvenile mice. Since the brain continues to

This article is freely accessible online.

Correspondence to: Soon Ae Kim, MD, Ph.D., Department of Pharmacology, School of Medicine, Eulji University,77, Gyeryongro 771beon-gil, Jung-gu, Daejeon 34824, Republic of Korea. Tel: +82 422591672, e-mail: sakim@eulji.ac.kr

Key Words: Trimethyltin, mitochondria, estrogen, sex difference. develop during puberty, the adolescent brain is particularly vulnerable (8). TMT is likely to act as an environmental toxin in people of all ages, as low concentrations of TMT are observed even in people with no exposure experience (9). Therefore, it is crucial to know the effects and mechanisms of TMT on the adolescent brain.

Furthermore, sex differences are known to be involved in the incidence of brain diseases (10-13). To understand the differences between male and female brains causing these phenomena, a growing number of evidence suggests that both male and female models should be included in animal and cell experiments (14). Glucocorticoids and sex hormones are considered important factors for understanding sex differences in various physiological phenomena. Several reports have suggested that these hormones play a beneficial role in brain metabolism $(15,16)$ and disease risk (17-19). Since puberty sex hormones also have an organizational effect on the central nervous system; they can have longterm behavioral effects (20). However, sex differences in pubertal hormone metabolism following acute chemical exposure have been scarcely investigated.

In the present study, following TMT administration, we determined how TMT treatment affects the concentration and metabolism of metabolic steroids in female and male 4week-old early juvenile mice brains.

\section{Materials and Methods}

Animal model. Three-week-old C57BL/6 mice were obtained from Samtako Bio Korea (Osan, Korea), and underwent adaptation in a room with controlled temperature $\left(22 \pm 2^{\circ} \mathrm{C}\right)$, humidity $(50 \pm 10 \%)$, and a $12 \mathrm{~h} \mathrm{light/dark} \mathrm{cycle,} \mathrm{with} \mathrm{free} \mathrm{access} \mathrm{to} \mathrm{water} \mathrm{and} \mathrm{food.} \mathrm{After}$ one week, mice were intraperitoneally administered either 2.3 $\mathrm{mg} / \mathrm{kg}$ TMT diluted in normal saline (TMT group) or normal saline (control group). Both groups were administered $20 \mathrm{ml} / \mathrm{kg}$ solutions. After $24 \mathrm{~h}$, mice were sacrificed using isoflurane (Hana Pharm, Seoul, Republic of Korea) anesthesia, and brains were excised and stored at $-80^{\circ} \mathrm{C}$. All procedures were conducted in accordance with the guidelines of the Eulji University Institutional Animal Care and Usage Committee (IACUC, document number: EUIACUC-17-12) and the ARRIVE guide for the care and use of laboratory animals. 
Western blotting. Total protein from the mouse brain cortex was isolated using the RIPA buffer (ATTO, Tokyo, Japan). Protein concentrations were measured using the bicinchoninic acid (BCA) assay. Briefly, $20 \mu \mathrm{g}$ of cytosolic protein were separated on $10 \%$ SDS-PAGE gels and transferred to nitrocellulose membranes (Pall, Port Washington, NY, USA). Next, the membranes were blocked with $5 \%$ non-fat milk in TBST buffer for $1 \mathrm{~h}$ at $4^{\circ} \mathrm{C}$ and incubated with primary anti-CYP1B1 antibody (Abcam, Cambridge, MA, USA) at $4^{\circ} \mathrm{C}$ overnight. The membranes were rinsed with TBST (Tris-buffered saline, $0.1 \%$ Tween 20 ) buffer, and incubated with horseradish peroxidase-labeled secondary antibody (Santa Cruz Biotechnology, Dallas, TX, USA) for $1 \mathrm{~h}$. After washing with TBST buffer, the membranes were incubated with West Femto Maximum Sensitivity Substrate (Thermo Fisher, Waltham, MA, USA). Protein expression levels were detected by exposure to an X-ray film (Agfa, Mortsel, Antwerp, Belgium), and analyzed using the ImageJ software (NIH, Bethesda, MD, USA).

Total RNA isolation and quantitative PCR. Total tissue DNA from mice cortices, was extracted using the miRNeasy mini kit (Qiagen, Hilden, Germany), and cDNA was synthesized from isolated RNA using the RT2 first strand kit (Qiagen). Target gene amplification was performed using $\mathrm{iQ}^{\mathrm{TM}} \mathrm{SYBR}^{\circledR}$ Green Supermix (Bio-rad, Hercules, CA, USA) in a CFX96 $6^{\mathrm{TM}}$ Real-Time system (Bio-rad). Gene expression was normalized to GAPDH. GAPDH primer sequences were as follows: forward, 5'-GAGTCAACGGATTTGGT CGT-3'; reverse, 5'-GATCTCGCTCCTGGAAGATG-3'. CYP1B1 primer sequences were; forward, 5'-GAGGACTTTGATCCA GCCCG-3'; reverse, 5'-TGGAGATGAAGAGAAACAGAAGCA3'. Relative mRNA expression was assessed using the $2^{-\Delta \Delta C t}$ method.

Preparation of cortical tissue samples. Cerebral cortical samples were prepared as previously described (21). Briefly, $20 \mu \mathrm{l}$ of the internal standard mixture was added to the sample $(50 \mathrm{ng} / \mathrm{ml})$ and then homogenized in $1 \mathrm{ml}$ of methanol/acetic acid $(99: 1, \mathrm{v} / \mathrm{v})$. After overnight extraction at $4^{\circ} \mathrm{C}$, the samples were centrifuged at $6,652 \times g$ for $5 \mathrm{~min}$, and pellets were extracted twice with $1 \mathrm{ml}$ of $\mathrm{MeOH} /$ acetic acid $(99: 1, v / v)$. Next, the organic phases were combined and dried under a nitrogen stream. The samples were resuspended in $1 \mathrm{ml}$ of $\mathrm{MeOH} /$ water (10:90, v/v). The mixture was extracted with Oasis PRiME HLB SPE cartridges (Waters Corporation, Milford, MA, USA). Then, the combined methanol eluates were evaporated under a nitrogen stream and dissolved in methanol $(100 \mu \mathrm{l})$. Finally, $5 \mu \mathrm{l}$ of this solution was injected into the liquid chromatography with tandem mass spectrometry (LC-MS/MS) system.

Metabolic profiling of steroids using LC-MS/MS. LC-MS/MS analysis was performed using an Acquity UPLC I-Class system (Waters Corporation), interfaced with a Xevo TQ-S micro tandem mass spectrometer (Waters Corporation) and an electrospray ionization (ESI) source. Chromatographic separation was achieved with an Acquity UPLC BEH C18 octadecylsilane column $(2.1 \mathrm{~mm}$ $\times 100 \mathrm{~mm}, 1.7 \mu \mathrm{m}$, Waters Corporation). For separation, the LC conditions were as follows: mobile phase $\mathrm{A}$ was $0.2 \mathrm{mM}$ ammonium fluoride in $\mathrm{H}_{2} \mathrm{O}$, and mobile phase $\mathrm{B}$ was $0.2 \mathrm{mM}$ ammonium fluoride in methanol. The gradient program $(\mathrm{v} / \mathrm{v})$ was performed at a flow rate of $400 \mu \mathrm{l} / \mathrm{min}$ and was initiated with $30 \% \mathrm{~B}(\mathrm{v} / \mathrm{v})$, maintained at $30 \% \mathrm{~B}(\mathrm{v} / \mathrm{v})$ for $5 \mathrm{~min}$, increased to $50 \% \mathrm{~B}(\mathrm{v} / \mathrm{v})$ at $15 \mathrm{~min}$, maintained at $50 \% \mathrm{~B}(\mathrm{v} / \mathrm{v})$ for $5 \mathrm{~min}$, increased to $55 \% \mathrm{~B}$ $(\mathrm{v} / \mathrm{v})$ at $23 \mathrm{~min}$, increased to $80 \% \mathrm{~B}(\mathrm{v} / \mathrm{v})$ at $27 \mathrm{~min}$, and then maintained at $80 \% \mathrm{~B}(\mathrm{v} / \mathrm{v})$ for $3 \mathrm{~min}$. Then, the column was reequilibrated for $3 \mathrm{~min}$ with $30 \% \mathrm{~B}(\mathrm{v} / \mathrm{v})$. The source and operating parameters were optimized as follows: capillary voltage of $3 \mathrm{kV}$ (ESI+) and $4 \mathrm{kV}$ (ESI-); cone gas flow of $30 \mathrm{l} / \mathrm{h}$; desolvation temperature of $450^{\circ} \mathrm{C}$; desolvation gas flow of $800 \mathrm{l} / \mathrm{h}$. Quantitative analysis was performed in the multiple reaction monitoring (MRM) mode. Data acquisition was performed using the MassLynx software (V4.1, Waters Corporation).

Statistical analysis. All statistical analyses were conducted using IBM SPSS Statistics for Windows (version 20, IBM Corporation, Armonk, NY, USA). Quantitative results are expressed as mean \pm standard deviation, and groups were compared using Dunnett's test and unpaired $t$-test. Differences were considered statistically significant at a $p$-value less than $0.05 \quad(p<0.05)$. Significant $p$-value data are denoted in the graphs as follows: ${ }^{*} p<0.05, * * p<0.01$, and $* * * p<0.001$.

\section{Results}

Alterations in metabolic steroid levels in the cerebral cortex of acute TMT-treated mice. To investigate the profile of metabolic steroids in male and female brains following TMT treatment, we performed an LC-MS/MS analysis. As expected, there was no significant difference in estradiol levels between 4-week-old female and male mice before TMT treatment. After TMT treatment, cortisol levels increased in both male and female brains (Figure 1A). In the male mouse brain, there was no change in estradiol levels after TMT administration (Figure 1B). The estradiol levels decreased, and the estradiol metabolite, 4-hydroxyestradiol levels increased in the female brain after TMT treatment (Figure 1C).

Sex-specific change in CYPIBI mRNA and protein levels in the cerebral cortex of acute TMT-treated mice. We measured mRNA and protein levels of cytochrome P450 1B1(CYP1B1), an enzyme that metabolizes estradiol using real-time PCR and western blotting. Interestingly, increased CYP1B1 mRNA levels were observed only in the female cortex after TMT treatment (Figure 2A). Furthermore, it was confirmed by western blot analysis that CYP1B1 protein levels were increased only in the TMT treated female cortex (Figure 2B).

\section{Discussion}

It is known that oxidative stress is associated with the induction of neurosteroid biosynthesis in the human brain, and TMT induces oxidative stress by mitochondrial dysfunction (22). Following TMT treatment, the cortisol levels, a representative stress hormone, increased in the brains of both male and female mice in this study. High cortisol levels have been reported to be associated with low 
A

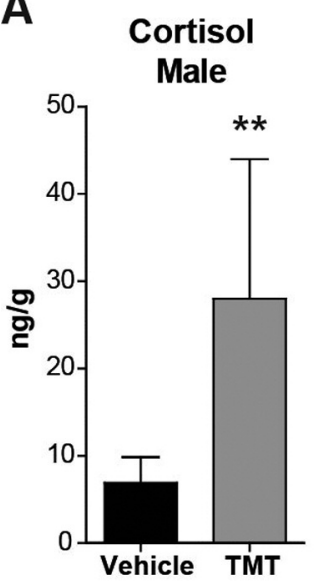

B
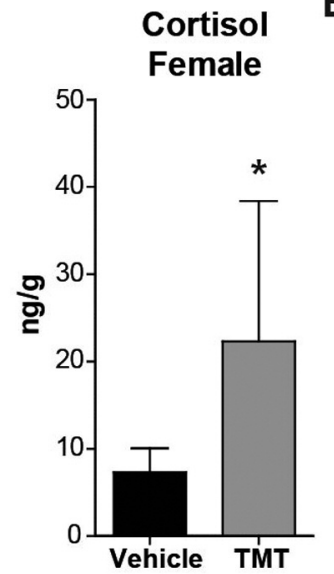

Estradiol Male

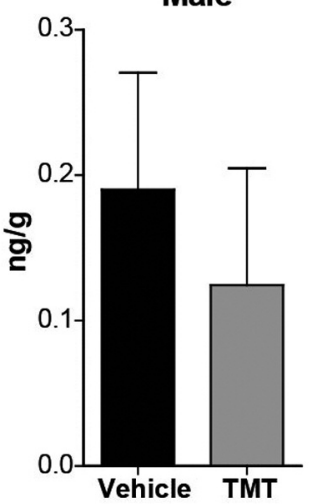

C

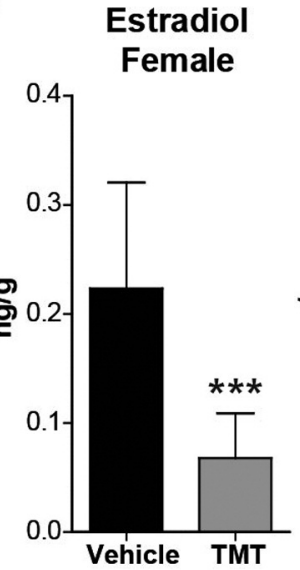

4-OH estradiol Female

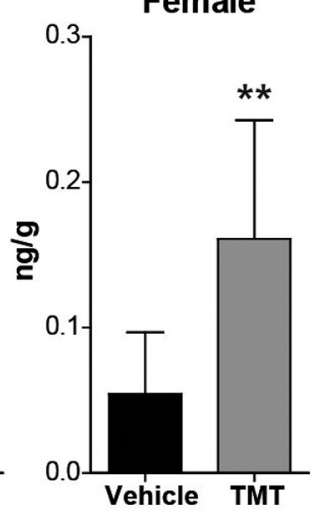

Figure 1. Changes in brain metabolic steroid levels in male and female mice brains. A. Cortisol levels in male (left, $n=10)$ and female ( $n=9)$ mice brains. B. Estradiol levels in male (left, $n=10)$. C. Estradiol (left, $n=9)$ and 4-OH estradiol levels (right, vehicle, $n=9$, TMT, $n=10)$ in female mice brains. Steroid levels were measured by LC-MS/MS analysis. *p<0.05,**p<0.01, ***p<0.001.

A

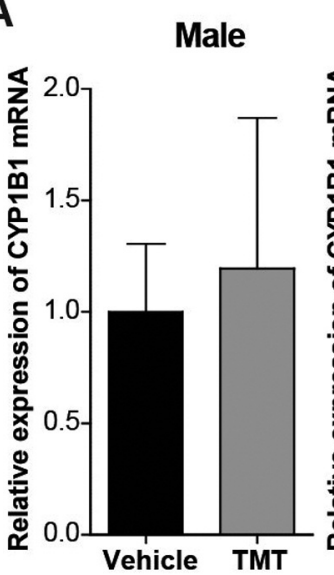

Female

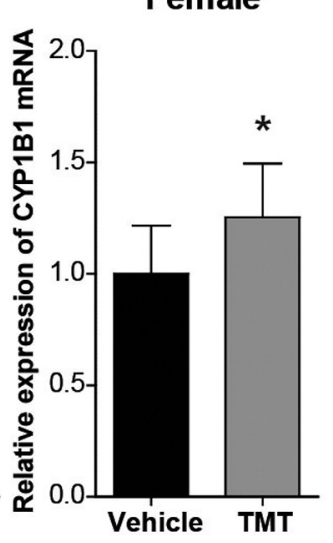

B

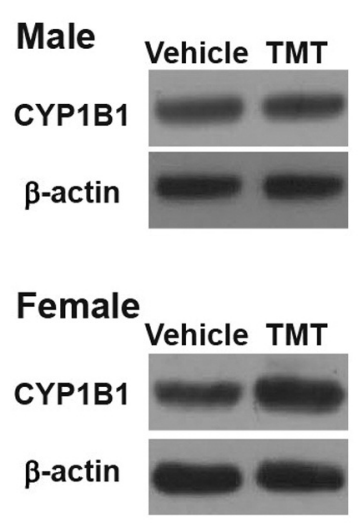

Male

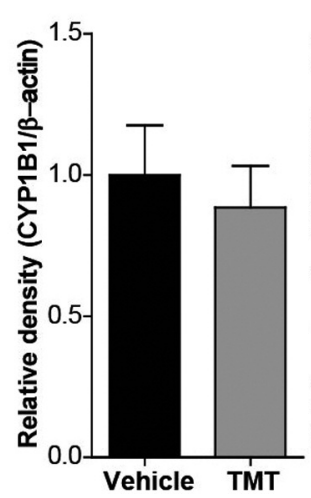

Female

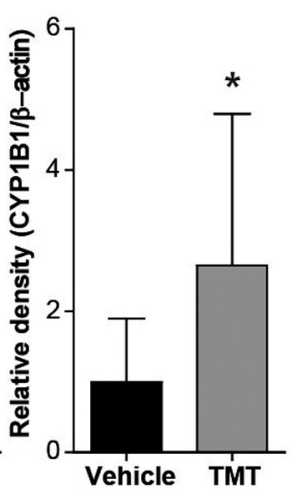

Figure 2. Changes in CYP1B1 expression in male and female mice brains. A. Relative expressions of CYP1B1 mRNA measured by RT-PCR in male (left, $n=10)$ and female (right, $n=8)$ mice brains. B. Representative western blots (left). Quantification of CYP1B1 protein levels in male ( $n=)$ and female $(n=8)$ mice brains (right). ${ }^{*} p<0.05$.

brain volume, memory impairment, and corticosterone treatment as well as changes in GABA uptake in the hippocampus, suggesting a mechanism for hormonal modulation of brain function $(23,24)$.

Estrogen is the primary female hormone, demonstrating pleiotropic effects on non-reproductive organs. Estradiol, a predominant and potent form of estrogen, plays an essential role in brain development and proper brain functioning, including mood and various cognitive activities (25). Several previous studies have shown the neuroprotective effects of estradiol in neurodegenerative diseases $(26,27)$. To the best of our knowledge, only two studies have investigated the effects of estradiol in TMT-induced animal brain damage. In one study, pharmacological administration of estradiol in TMT-treated 2-month-old rats upregulated genes involved in neuroprotection and synaptogenesis (28). In the second study, pretreatment with estradiol reduced neuronal death in TMTtreated neonatal rats (29). It has recently been suggested that 4-hydroxyestrone can protect neuronal cells from oxidative damage (30). In this study, we observed increased 4hydroxyestrone levels in TMT treated females, which may be a neuroprotective in vivo homeostatic response.

Notably, there are numerous differences in the brains of females and males regarding metabolism. Using aged mice, Zhao et al. have reported altered expression of genes involved in metabolism between female and male rats (31). Our study 
revealed, for the first time, that the levels of endogenous estradiol and its metabolite were altered in the female brain after TMT exposure. Additionally, TMT exposure induced CYP1B1 expression only in female mice. Our data suggest that it is crucial to evaluate estrogen metabolism to elucidate the mechanism of TMT toxicity concerning sex differences. Reportedly, CYP1B1 expression is regulated by the aryl hydrocarbon receptor (AhR) (32), which is a ligand-activated transcription factor that controls gene expression induced by xenobiotics (33). Increased 4-hydroxyestradiol, an estradiol metabolite produced via CYP1B1, may be induced by the AhR pathway via TMT acting as a xenobiotic $(34,35)$. Moreover, the AhR pathway has been reported to cross-talk with nuclear receptor pathways and be involved in neuronal progenitor cell expansion and the sex-dependent differentiation of GABAergic neurons in the hippocampus (36). As studies investigating the effects of 4hydroxyestradiol and the mechanism of sex-dependent CYP1B1 induction are lacking, further research is warranted, especially regarding sex-specific differences concerning steroid metabolism in the brain.

In this study, we first demonstrated that short-term TMT treatment in early-juvenile mice induced sex-specific alterations in brain estrogen metabolism. To the best of our knowledge, this is the first study to identify differences in estradiol metabolism between the brains of male and female mice in the earlier life stage, indicating that male and female brains differ in metabolic characteristics prior to significant sexual maturation. Our results present a new perspective on neurological disorders that can occur in men and women when accidentally exposed to environmental neurotoxins such as TMT at an early age.

\section{Conflicts of Interest}

The Authors declare that they have no known competing financial interests or personal relationships that could have appeared to influence the work reported in this paper.

\section{Authors' Contributions}

Jung Ho Lee: data analysis, paper writing. Eun Hye Jang: cell culture, animal treatment, biochemical experiments, manuscript writing. Sung-Hee Cho: LC-MS/MS, data analysis, manuscript revision, made a critical contribution to the discussion. Soon Ae Kim: overall design, manuscript revision.

\section{Acknowledgements}

This work was supported by the National Research Foundation of Korea (NRF) grant funded by the Korean government, MOE, and MSIT (No. 2017R1D1A3B03033533 and No. 2020R1A2 C1009499). MOE and MSIT were not involved in the preparation or submission of this manuscript.

\section{References}

1 Wang X, Cai J, Zhang J, Wang C, Yu A, Chen Y and Zuo Z: Acute trimethyltin exposure induces oxidative stress response and neuronal apoptosis in sebastiscus marmoratus. Aquat Toxicol 90(1): 58-64, 2008. PMID: 18801585. DOI: 10.1016/j.aquatox. 2008.07.017

2 Balaban CD, O'Callaghan JP and Billingsley ML: Trimethyltininduced neuronal damage in the rat brain: Comparative studies using silver degeneration stains, immunocytochemistry and immunoassay for neuronotypic and gliotypic proteins. Neuroscience 26(1): 337-361, 1988. PMID: 2458546. DOI: 10.1016/0306-4522(88)90150-9

3 Kawada K, Yoneyama M, Nagashima R and Ogita K: In vivo acute treatment with trimethyltin chloride causes neuronal degeneration in the murine olfactory bulb and anterior olfactory nucleus by different cascades in each region. J Neurosci Res 86(7): 16351646, 2008. PMID: 18183623. DOI: 10.1002/jnr.21612

4 Fortemps E, Amand G, Bomboir A, Lauwerys R and Laterre EC: Trimethyltin poisoning. Report of two cases. Int Arch Occup Environ Health 41(1): 1-6, 1978. PMID: 627412. DOI: 10.1007/bf00377794

5 Brown AW, Aldridge WN, Street BW and Verschoyle RD: The behavioral and neuropathologic sequelae of intoxication by trimethyltin compounds in the rat. Am J Pathol 97(1): 59-82, 1979. PMID: 495696.

6 Stanton ME, Jensen KF and Pickens CV: Neonatal exposure to trimethyltin disrupts spatial delayed alternation learning in preweanling rats. Neurotoxicol Teratol 13(5): 525-530, 1991. PMID: 1758406. DOI: 10.1016/0892-0362(91)90060-a

7 Miyake K, Misawa T, Aikawa H, Yoshida T and Shigeta S: The effects of prenatal trimethyltin exposure on development and learning in the rat. Sangyo Igaku 31(5): 363-371, 1989. PMID: 2585816. DOI: 10.1539 /joh1959.31.363

8 Tschann JM, Adler NE, Irwin CE, Jr., Millstein SG, Turner RA and Kegeles SM: Initiation of substance use in early adolescence: The roles of pubertal timing and emotional distress. Health Psychol 13(4): 326-333, 1994. PMID: 7957011. DOI: 10.1037//0278-6133.13.4.326

9 Braman RS and Tompkins MA: Separation and determination of nanogram amounts of inorganic tin and methyltin compounds in the environment. Anal Chem 51(1): 12-19, 1979. PMID: 420393. DOI: $10.1021 / \mathrm{ac} 50037 \mathrm{a} 011$

10 Brookmeyer R, Evans DA, Hebert L, Langa KM, Heeringa SG, Plassman BL and Kukull WA: National estimates of the prevalence of alzheimer's disease in the united states. Alzheimers Dement 7(1): 61-73, 2011. PMID: 21255744. DOI: 10.1016/j.jalz.2010.11.007

11 Alzheimer's Association: 2013 Alzheimer's disease facts and figures. Alzheimers Dement 9(2): 208-245, 2013. PMID: 23507120. DOI: 10.1016/j.jalz.2013.02.003

12 Salk RH, Hyde JS and Abramson LY: Gender differences in depression in representative national samples: Meta-analyses of diagnoses and symptoms. Psychol Bull 143(8): 783-822, 2017. PMID: 28447828. DOI: 10.1037/bul0000102

13 Reeves MJ, Bushnell CD, Howard G, Gargano JW, Duncan PW, Lynch G, Khatiwoda A and Lisabeth L: Sex differences in stroke: Epidemiology, clinical presentation, medical care, and outcomes. Lancet Neurol 7(10): 915-926, 2008. PMID: 18722812. DOI: $10.1016 / \mathrm{s} 1474-4422(08) 70193-5$ 
14 Clayton JA and Collins FS: Policy: Nih to balance sex in cell and animal studies. Nature 509(7500): 282-283, 2014. PMID: 24834516. DOI: $10.1038 / 509282 \mathrm{a}$

15 Li R, He P, Cui J, Staufenbiel M, Harada N and Shen Y: Brain endogenous estrogen levels determine responses to estrogen replacement therapy via regulation of bace1 and nep in female alzheimer's transgenic mice. Mol Neurobiol 47(3): 857-867, 2013. PMID: 23180279. DOI: $10.1007 / \mathrm{s} 12035-012-8377-3$

16 Yue X, Lu M, Lancaster T, Cao P, Honda S, Staufenbiel M, Harada N, Zhong Z, Shen Y and Li R: Brain estrogen deficiency accelerates abeta plaque formation in an alzheimer's disease animal model. Proc Natl Acad Sci USA 102(52): 19198-19203, 2005. PMID: 16365303. DOI: 10.1073/pnas.0505203102

17 Ennis GE, An Y, Resnick SM, Ferrucci L, O'Brien RJ and Moffat SD: Long-term cortisol measures predict alzheimer disease risk. Neurology 88(4): 371-378, 2017. PMID: 27986873. DOI: $10.1212 / \mathrm{wnl} .0000000000003537$

18 Pietrzak RH, Laws SM, Lim YY, Bender SJ, Porter T, Doecke J, Ames D, Fowler C, Masters CL, Milicic L, Rainey-Smith S, Villemagne VL, Rowe CC, Martins RN and Maruff P: Plasma cortisol, brain amyloid-beta, and cognitive decline in preclinical alzheimer's disease: A 6-year prospective cohort study. Biol Psychiatry Cogn Neurosci Neuroimaging 2(1): 45-52, 2017. PMID: 29560886. DOI: 10.1016/j.bpsc.2016.08.006

19 Lv W, Du N, Liu Y, Fan X, Wang Y, Jia X, Hou X and Wang B: Low testosterone level and risk of alzheimer's disease in the elderly men: A systematic review and meta-analysis. Mol Neurobiol 53(4): 2679-2684, 2016. PMID: 26154489. DOI: 10.1007/s12035-015-9315-y

20 Sisk CL and Zehr JL: Pubertal hormones organize the adolescent brain and behavior. Front Neuroendocrinol 26(3-4): 163-174, 2005. PMID: 16309736. DOI: 10.1016/j.yfrne.2005.10.003

21 Pesaresi M, Maschi O, Giatti S, Garcia-Segura LM, Caruso D and Melcangi RC: Sex differences in neuroactive steroid levels in the nervous system of diabetic and non-diabetic rats. Horm Behav 57(1): 46-55, 2010. PMID: 19422828. DOI: 10.1016/j.yhbeh.2009.04.008

22 Qu M, Zhou Z, Chen C, Li M, Pei L, Chu F, Yang J, Wang Y, Li L, Liu C, Zhang L, Zhang G, Yu Z and Wang D: Lycopene protects against trimethyltin-induced neurotoxicity in primary cultured rat hippocampal neurons by inhibiting the mitochondrial apoptotic pathway. Neurochem Int 59(8): 1095-1103, 2011. PMID: 22032970. DOI: 10.1016/j.neuint.2011.10.005

23 Echouffo-Tcheugui JB, Conner SC, Himali JJ, Maillard P, DeCarli CS, Beiser AS, Vasan RS and Seshadri S: Circulating cortisol and cognitive and structural brain measures: The framingham heart study. Neurology 91(21): e1961-e1970, 2018. PMID: 30355700. DOI: 10.1212/wnl.0000000000006549

24 Ratner MH, Kumaresan V and Farb DH: Neurosteroid actions in memory and neurologic/neuropsychiatric disorders. Front Endocrinol (Lausanne) 10: 169, 2019. PMID: 31024441. DOI: 10.3389/fendo.2019.00169

25 Cutter WJ, Norbury R and Murphy DG: Oestrogen, brain function, and neuropsychiatric disorders. J Neurol Neurosurg Psychiatry 74(7): 837-840, 2003. PMID: 12810759. DOI: 10.1136/jnnp.74.7.837
26 Cho JJ, Iannucci FA, Fraile M, Franco J, Alesius TN and Stefano GB: The role of the estrogen in neuroprotection: Implications for neurodegenerative diseases. Neuro Endocrinol Lett 24(3-4): 141-147, 2003. PMID: 14523347.

27 Spence RD and Voskuhl RR: Neuroprotective effects of estrogens and androgens in cns inflammation and neurodegeneration. Front Neuroendocrinol 33(1): 105-115, 2012. PMID: 22209870. DOI: 10.1016/j.yfrne.2011.12.001

28 Corvino V, Di Maria V, Marchese E, Lattanzi W, Biamonte F, Michetti F and Geloso MC: Estrogen administration modulates hippocampal gabaergic subpopulations in the hippocampus of trimethyltin-treated rats. Front Cell Neurosci 9: 433, 2015. PMID: 26594149. DOI: 10.3389/fncel.2015.00433

29 Marchese E, Corvino V, Di Maria V, Furno A, Giannetti S, Cesari E, Lulli P, Michetti F and Geloso MC: The neuroprotective effects of 17beta-estradiol pretreatment in a model of neonatal hippocampal injury induced by trimethyltin. Front Cell Neurosci 12: 385, 2018. PMID: 30416427. DOI: 10.3389/fncel.2018.00385

30 Choi HJ, Lee AJ, Kang KS, Song JH and Zhu BT: 4hydroxyestrone, an endogenous estrogen metabolite, can strongly protect neuronal cells against oxidative damage. Sci Rep 1O(1): 7283, 2020. PMID: 32350290. DOI: 10.1038/s41598020-62984-y

31 Zhao L, Mao Z, Woody SK and Brinton RD: Sex differences in metabolic aging of the brain: Insights into female susceptibility to alzheimer's disease. Neurobiol Aging 42: 69-79, 2016. PMID: 27143423. DOI: $10.1016 / \mathrm{j}$.neurobiolaging.2016.02.011

32 Alexander DL, Eltom SE and Jefcoate CR: Ah receptor regulation of cyp 1 b1 expression in primary mouse embryoderived cells. Cancer Res 57(20): 4498-4506, 1997. PMID: 9377560.

33 Szychowski KA, Wnuk A, Kajta M and Wojtowicz AK: Triclosan activates aryl hydrocarbon receptor (ahr)-dependent apoptosis and affects cyp1a1 and cyp1b1 expression in mouse neocortical neurons. Environ Res 151: 106-114, 2016. PMID: 27474938. DOI: 10.1016/j.envres.2016.07.019

34 Dawling S, Hachey DL, Roodi N and Parl FF: In vitro model of mammary estrogen metabolism: Structural and kinetic differences between catechol estrogens 2- and 4hydroxyestradiol. Chem Res Toxicol 17(9): 1258-1264, 2004. PMID: 15377160. DOI: 10.1021/tx0498657

35 DuSell CD, Nelson ER, Wittmann BM, Fretz JA, Kazmin D, Thomas RS, Pike JW and McDonnell DP: Regulation of aryl hydrocarbon receptor function by selective estrogen receptor modulators. Mol Endocrinol 24(1): 33-46, 2010. PMID: 19901195. DOI: 10.1210/me.2009-0339

36 Petersen SL, Krishnan S and Hudgens ED: The aryl hydrocarbon receptor pathway and sexual differentiation of neuroendocrine functions. Endocrinology 147(6 Suppl): S33-42, 2006. PMID: 16690800. DOI: 10.1210/en.2005-1157

Received December 10, 2020 Revised January 10, 2021 Accepted January 11, 2021 